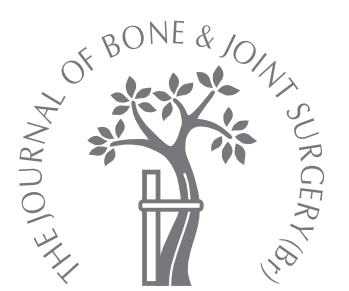

C. W. McBryde, K. Dehne, A. M. Pearson, R. B. C. Treacy, P. B. Pynsent

From The Royal Orthopaedic Hospital, Birmingham, England

\title{
One- or two-stage bilateral metal-on-metal hip resurfacing arthroplasty
}

\begin{abstract}
Patients considered suitable for total hip resurfacing arthroplasty often have bilateral disease. The peri-operative complications, transfusion requirements, hospital stay, outcome and costs in patients undergoing one-stage bilateral total hip resurfacing were compared with a group of patients undergoing a two-stage procedure. A total of 92 patients were included in the study, of which $37(40 \%)$ had a one-stage and $55(60 \%)$ had a two-stage resurfacing. There were no significant differences in age, gender, or American Society of Anaesthesiologists grade between the groups $(p=0.31, p=0.23, p=0.13$, respectively). There were three systemic complications in the one-stage group $(8.1 \%)$ and one in the two-stage group (1.8\% of patients; $0.9 \%$ of procedures). There was no significant difference in the complication rate $(p=0.72)$ or the transfusion requirements $(p=0.32)$ between the two groups. The one-stage group had a reduced total hospital stay of five days $(95 \%$ confidence interval 4.0 to $6.9 ; p<0.001)$, reduced length of time to completion of all surgery of five months (95\% confidence interval 2.6 to $8.3 ; p<0.001)$, and the reduced cost was $35 \%$ less than that of a two-stage procedure. However, the total anaesthetic time was significantly longer for the one-stage group ( $p<0.001 ; 95 \%$ confidence interval 31 to 52 ).

This study demonstrates that consideration should be given to one-stage surgery for patients with bilateral symptomatic disease suitable for metal-on-metal hip resurfacing. A one-stage procedure appears to have benefits for both the patient and the hospital without additional complications.
\end{abstract}

Metal-on-metal hip resurfacing is increasing in popularity and medium-term results are now available. ${ }^{1-5}$ Patients considered suitable for this procedure often have symptomatic bilateral disease. Generally they are relatively young, in employment, may participate in a variety of sports, and wish to return to these activities following treatment. A benefit of a one-stage procedure for these patients would be a reduction in the period of incapacity. Comparisons between a one- and a two-stage bilateral approach in total hip replacement (THR) have been published with conflicting findings. Concerns have been raised regarding increased complications in the one-stage approach; $;^{6-8}$ in particular an increased risk of pulmonary complications was found in a large retrospective comparative study. ${ }^{7}$ In contrast, it has been reported that a one-stage approach is effective in relieving pain and improving function without significantly increasing morbidity or mortality. ${ }^{9-17} \mathrm{~A}$ recent prospective randomised study comparing one- and twostage hip replacement has reported that intraoperative complications, peri-operative mor- bidity, overall operating time, functional score and rate of survival were not significantly different in the two groups. ${ }^{15}$ The benefits of a one-stage over a two-stage procedure were found to be a significantly lower blood loss and shorter hospital stay. A further prospective study compared one-stage bilateral with unilateral THR. ${ }^{11}$ This study reported that the 90day mortality, and individual major and minor complications were not significantly different. However, the study also found that transfusion requirements were greater in the bilateral group, but did not report if the unilateral group had further surgery to the contralateral hip and, if so, whether a further transfusion was required. In a further study, the financial cost per patient treated for bilateral disease in one stage was approximately $25 \%$ less than that of a two-stage THR. ${ }^{18}$

The authors are unaware of any published data comparing one- and two-stage hip resurfacing for bilateral disease. This study aimed to compare the peri-operative complications, transfusion requirements, length of hospital stay, outcome and costs in patients undergoing 
one-stage bilateral total hip resurfacing, with a group of patients undergoing a two-stage procedure.

\section{Patients and Methods}

Between July 1994 and August 2006, 2729 hip resurfacing procedures were performed at our institution and details recorded on a database. From this database we identified 37 patients who had bilateral hip resurfacing under a single anaesthetic. These patients comprised the one-stage group. We also identified 55 patients who had two-stage bilateral hip resurfacing with more than one day and less than 12 months between the two procedures. The two-stage group included bilateral surgery during the same hospital admission. The age, gender, diagnosis, American Society of Anaesthesiologists (ASA) grade ${ }^{19}$ and Oxford hip score ${ }^{20}$ were recorded pre-operatively. The most symptomatic hip was always treated first. The decision whether the patient was suitable for a bilateral procedure was made by the operating surgeon (AMP or RBCT) in conjunction with the patient. A subset from the two-stage group who had symptomatic bilateral disease at presentation and who were considered sufficiently fit based on their ASA grade for a one-stage procedure, but who underwent a two-stage procedure, was also identified.

All procedures were performed via a posterior approach and were carried out in a laminar airflow operating theatre. The study-group underwent a hybrid metal-on-metal procedure with an uncemented acetabular component and cemented femoral component using the surgical technique previously reported. ${ }^{3}$ Between July 1994 and December 1996, patients had a McMinn hip resurfacing arthroplasty implanted (Corin Medical, Cirencester, United Kingdom) and from August 1997 onwards, the Birmingham Hip Resurfacing arthroplasty was used (Smith and Nephew, London, United Kingdom). For the one-stage procedure the first hip was completed in the routine fashion and the wound dressed prior to all the operating team unscrubbing and turning the patient. With the agreement of the anaesthestist the second side was then undertaken in the routine fashion. Where the anaesthetist deemed it unsafe to continue with the second side this was recorded. At the discretion of the operating surgeon a suction drain was or was not used in each hip for post-operative drainage. In the onestage group the operating time was calculated as the time between the induction of anaesthesia and skin closure on the second hip, and in the two stage group as the sum of the time between the induction and skin closure in each operation. Any intra-operative complications including notching of the femoral neck were recorded. Full weight-bearing was allowed from the first day post-operatively. The haemoglobin was measured on the first and, if necessary, the third post-operative days and any blood transfusion was recorded. The length of hospital stay was calculated from the day of admission to the day of discharge. For patients in the two-stage group in which the operation was performed on separate admissions the sum of the two admissions was calculated. Local complications such as fracture of the neck of the femur, dislocation, superficial and deep-wound infection were recorded. Systemic complications, including cardiac, respiratory, gastrointestinal, pulmonary embolism and ultrasound-proven deep-vein thrombosis were noted. Patients were followed up clinically with the completion of an Oxford hip score at six weeks, six months and then annually thereafter, together with a radiological review at each of these visits. The Oxford hip score was scored as a percentage of the questions answered. ${ }^{21}$ Forms with less than 11 questions answered were discarded.

Current funding arrangements for the United Kingdom National Health Service (NHS) provide reimbursement for the hospital per in-patient episode at nationally agreed rates for individual procedures and the associated peri-operative care. The 2006 scales provided $£ 6338$ for up to an 18 -day stay and then $£ 150$ per day after that for a one-stage bilateral hip resurfacing. ${ }^{22}$ A two-stage bilateral procedure was reimbursed at a unilateral rate of $£ 4690$ for each side up to a ten-day stay per side, and then at $£ 249$ per day thereafter. $^{22}$ Follow-up out-patient appointments were reimbursed at $£ 71$ per appointment. The total reimbursement received for each patient was calculated. ${ }^{22}$ No adjustment was made for the historical rates involved.

Statistical analysis was performed using the $\mathrm{R}$ program ${ }^{23}$ with $95 \%$ confidence intervals (CI) derived from the twosample $t$-test for continuous variables, the chi-squared test for dichotomous variables, and the Mann-Whitney test was used where appropriate. Where proportions were compared a two-sample test for equality of proportions with continuity correction was used. The level of significance was set at $\mathrm{p}<0.05$.

\section{Results}

All records for both study groups were available for analysis and no patient was excluded. There were no significant differences in age, gender and ASA grade between the two groups (Table I). One patient included in the two-stage group had been planned for a one-stage procedure. This patient was ASA grade 3 and had moderate aortic regurgitation and hypertension. During the operation following completion of the first side, the patient was deemed unfit by the anaesthetist to continue and the operation was finished at that point. The patient suffered no further complications and proceeded to have the second side operated on without complication four months later. The patient is included in the analysis in the two-stage group. During the study period no other patient for whom it was planned to proceed with a one-stage procedure was unable to complete their surgery under a single anaesthetic.

The mean total number of units of blood transfused per patient was 1.6 ( 0 to 7 ) in the one-stage group and 1.4 ( 0 to $7)$ in the two-stage group. This difference was not significant (Wilcoxon test, $\mathrm{p}=0.32$ ). One patient from each group required a total transfusion of 7 units. All the other patients required a total of 5 units or less. The mean anaes- 
Table I. Demographics, American Society of Anesthesiologists (ASA) grade and diagnosis of the one- and two-stage groups

\begin{tabular}{|c|c|c|c|c|}
\hline & One-stage $(n=37)$ & Two-stage ( $n=55$ ) & Total $(n=92)$ & p-value \\
\hline Mean age in years (range) & 51 (12 to 67$)$ & 48 (19 to 64$)$ & 49 (12 to 67$)$ & 0.31 (t-test) \\
\hline \multicolumn{5}{|l|}{ Gender } \\
\hline Male:female & 18:19 & $35: 20$ & $53: 39$ & 0.23 (chi-squared test) \\
\hline \multicolumn{5}{|l|}{ ASA grade $(\%)$} \\
\hline 1 & $21(56.7)$ & $29(52.7)$ & $50(54.3)$ & 0.13 (chi-squared test) \\
\hline II & 16 (43.3) & $20(36.3)$ & $36(39.1)$ & \\
\hline III & $0(0)$ & $6(11)$ & $6(6.6)$ & \\
\hline \multicolumn{5}{|l|}{ Diagnosis (\%) } \\
\hline Osteoarthritis & $29(78.4)$ & $41(74.5)$ & $70(76.1)$ & \\
\hline Osteonecrosis & $2(5.4)$ & $5(9.1)$ & $7(7.6)$ & \\
\hline Rheumatoid arthritis & $1(2.7)$ & $3(5.5)$ & $4(4.3)$ & \\
\hline Non-specific inflammatory arthritis & $0(0)$ & $2(3.6)$ & $2(2.2)$ & \\
\hline Developmental dysplasia & $2(5.4)$ & $4(7.3)$ & $6(6.5)$ & \\
\hline Slipped upper femoral epiphysis & $3(8.1)$ & $0(0)$ & $3(3.3)$ & \\
\hline
\end{tabular}

Table II. Complications in the one- and two-stage groups (percentage)

\begin{tabular}{|c|c|c|}
\hline & One-stage & Two-stage \\
\hline \multicolumn{3}{|l|}{ Surgical complication (per hip) } \\
\hline Superficial wound infection & 0 & $1(0.9)$ \\
\hline Notching of the femoral neck & 0 & $2(1.8)$ \\
\hline Dislocation & 0 & $1(0.9)$ \\
\hline \multicolumn{3}{|c|}{ Systemic complication (per patient) } \\
\hline Supraventricular tachycardia & $1(2.7)$ & 0 \\
\hline Paralytic ileus & $1(2.7)$ & 0 \\
\hline Diarrhoea & $1(2.7)$ & $1(1.8)$ \\
\hline Total & $3(8.1)$ & 5 (9.1 patients $/ 4.5$ hips) \\
\hline
\end{tabular}

thetic time was 133 minutes (90 to 180 ) in the one-stage group and 92 minutes (55 to 190) in the two-stage group with a significant mean difference of 41 minutes $(95 \%$ confidence interval (CI) 31 to 52; $t$-test, $\mathrm{p}<0.001)$. The mean total length of hospital stay was 11 days (7 to 17 ) in the one-stage group and 16 days (10 to 30$)$ in the two-stage group, with a significant mean difference of 5 days (95\% CI 4.0 to 6.9 ; $t$-test, $\mathrm{p}<0.001)$. A comparison was performed on a subset of 31 patients in the two-stage group who had symptomatic bilateral disease at presentation, and who would have been suitable for a one-stage procedure, with patients in the one-stage group. Further analysis showed the mean length of time from the need to resurface both hips to completion of surgery for the second hip was 6 months ( 2 to 16 ) for the one-stage group and 11 months ( 2 to 27 ) for the subset of the two-stage group, with a significant mean difference of 5 months (95\% CI 2.6 to 8.3 ; $t$-test, $\mathrm{p}<0.001$ ).

The peri- and post-operative complications are summarised in Table II. The four local complications in the two-stage group all occurred at the time of the second procedure. The superficial wound infection was successfully treated with oral antibiotics. The dislocation occurred at two weeks following surgery and was treated by a closed reduction under a general anaesthetic. No further problems were encountered with this patient during follow-up. The two patients whose femoral necks were notched were treated by a six-week period of partial weight-bearing with the use of crutches. There were three systemic complications in the one-stage group $(8.1 \%)$. One patient developed a supraventricular tachycardia during the first 24 hours post-operatively but this settled spontaneously and there were no recurrences. One patient developed a paralytic ileus which was treated by withholding oral intake, nasogastric aspiration, and intravenous fluid supplementation. One patient had a 24-hour episode of unexplained diarrhoea. In the two-stage group there was one systemic complication $(1.8 \%$ of patients or $0.9 \%$ of procedures) which occurred after the second procedure which was also an episode of unexplained diarrhoea. A proportion test did not demonstrate a significant difference between the two groups of systemic complications per patient or per procedure $(\mathrm{p}=0.35)$. All patients that suffered a complication made a full recovery.

The mean follow-up for the one-stage group was 1.25 years $(0.1$ to 5$)$ and for the two-stage group 2.83 years $(0.1$ to 10.9) following the second procedure. There were 410 Oxford hip scores available for analysis of which 117 were 


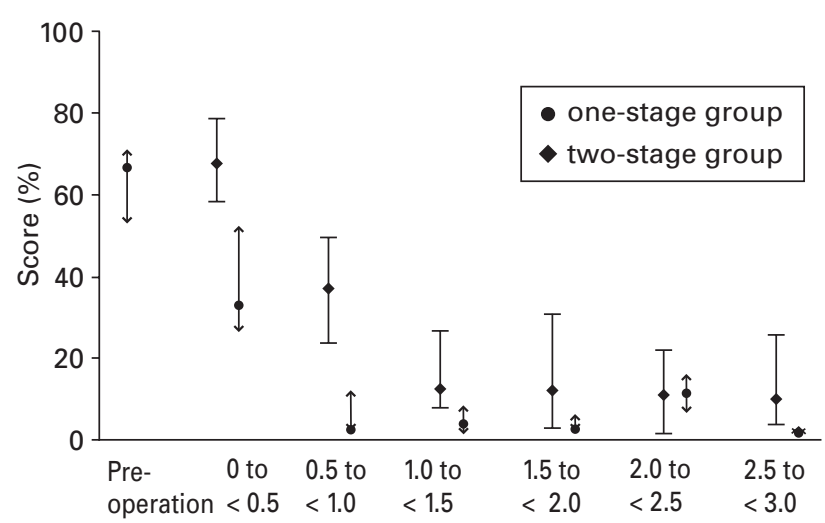

Time since operation (yrs)

Fig. 1

Plot of the median and interquartile ranges for Oxford hip scores. For the two-stage group only the scores for the second hip are shown and these have been displaced by the mean time difference of 5 months between the two procedures to illustrate the extended time of pain and loss of function.

for the one-stage, and 293 for the two-stage group. The median scores for the one-stage group and for the second stage of the two-stage group are shown in Figure 1. The two-stage scores have been displaced by the mean time between the stages. This demonstrated that the interquartile range of the two-stage group score did not fall to the same level as that of the one-stage group until 18 months after the first operation.

No patient had undergone or was awaiting a revision procedure during the study period.

The mean cost for treating the one-stage group was $£ 6338$ ( $£ 6338$ to $£ 6338$ ) per patient and for the two-stage group $£ 9726$ ( $£ 9380$ to $£ 11746$ ) per patient but this included a longer total hospital stay, two anaesthetics and a mean of two extra out-patient appointments. The single-stage procedure offered a $35 \%$ reduction in cost compared with the two-stage procedure.

\section{Discussion}

This study has demonstrated no detrimental effects when performing a one-stage bilateral metal-on-metal hip resurfacing arthroplasty in comparison with a two-stage procedure. The advantages of a one-stage procedure for bilateral disease included reduction in total hospital stay and time to completion of all surgery, a shortening of the period for which the patient experiences symptoms and a financial saving. These findings agree with those of Bhan et $\mathrm{al}^{15}$ who concluded that a single-stage is as safe as a two-stage procedure in patients of ASA grade 1 or 2 and probably also grade 3 . In this study three patients $(8.1 \%)$ in the one-stage group suffered a systemic complication in comparison with one $(1.8 \%)$ in the two-stage group. This was not a statisticallysignificant difference and all the patients fully recovered.
There was no significant difference in the blood transfusion requirements between the two groups and there does not appear to be a detrimental effect on outcome as measured by further surgery, revision or Oxford hip score during follow-up. Analysis of the Oxford hip score demonstrated that the one-stage group reached a low median score between six months and one year following surgery and the two-stage group reached a similar score six months to one year after the second procedure, implying the two-stage group experience symptoms for longer than the one-stage group by a period equal to the time between the two procedures (Fig. 1).

Surprisingly we found the total anaesthetic time was significantly longer in the one-stage group. This can be attributed to the time taken to undrape, reposition the patient redrape and prepare the patient again. In a previous study on THR, efforts were made to reduce the time for a one-stage procedure by having a second table and equipment available for immediate use following completion of the first side. ${ }^{15}$ The study reported the time from the last skin staple on the first hip to the skin incision on the second hip to between 15 and 20 minutes.

It has been reported previously that bilateral one-stage THR saves $25 \%$ of the cost of performing two unilateral procedures. ${ }^{16,18}$ A similar, but larger, saving has been found in this study.

As this is a retrospective study without randomisation, selection bias may play an important part in interpreting the results. The period of more than one day and less than 12 months between procedures was used to define the two-stage group. A different interval could have been applied but it was felt that the selected period would encompass most patients for whom a one-stage procedure may have been possible. In this study the decision on whether to proceed with a onestage operation was made by a surgeon experienced in hip resurfacing and a senior anaesthetist with an operating team who regularly perform these procedures. It would appear reasonable to offer one-stage surgery to patients with bilateral symptomatic disease when appropriate, but due consideration should be given to the experience of the operating team as well as the patients' suitability.

In support of the research for the preparation of this manuscript, one or more of the authors received grants from the British Hip Society (The McMinn Scholarship).

The author or one or more of the authors have received or will receive benefits for personal or professional use from a commercial party related directly or indirectly to the subject of this article. In addition, benefits have been or will be directed to a research fund, foundation, educational institution, or other nonprofit organisation with which one or more of the authors are associated.

\section{References}

1. No authors listed. NJR Steering Committee. National Joint Registry for England and Wales - 3rd annual clinical report. The NJR Centre, Hemel Hempstead, February 2006.

2. Daniel J, Pynsent PB, McMinn DJW. Metal-on-metal resurfacing of the hip in patients under the age of 55 years with osteoarthritis. J Bone Joint Surg [Br] 2004;86B:177-84

3. Treacy RBC, McBryde CW, Pynsent PB. Birmingham hip resurfacing arthroplasty: a minimum follow-up of five years. J Bone Joint Surg [Br] 2005;87-B:167-70. 
4. Pollard TCB, Baker RP, Eastaugh-Waring SJ, Bannister GC. Treatment of the young active patient with osteoarthritis of the hip: a five- to seven-year comparison of hybrid total hip arthroplasty and metal-on-metal resurfacing. J Bone Joint Surg $[B r]$ 2006;88-B:592-600

5. Revell MP, McBryde CW, Bhatnagar S, Pynsent PB, Treacy RBC. Metal-onmetal hip resurfacing on osteonecrosis of the femoral head. J Bone Joint Surg $[A m]$ 2006;88-A(Suppl 3):98-103.

6. Salvati EA, Hughes P, Lachiewicz P. Bilateral total hip-replacement arthroplasty in one stage. J Bone Joint Surg [Am] 1978;60-A:640-4.

7. Berend ME, Ritter MA, Harty LD, et al. Simultaneous bilateral versus unilatera total hip arthroplasty an outcome analysis. J Arthroplasty 2005;20:421-6.

8. Ritter MA, Randolph JC. Bilateral total hip arthroplasty: a simultaneous procedure. Acta Orthop Scand 1976;47:203-8.

9. Laursen J0, Husted H, Mossing NB. One-stage bilateral total hip arthroplasty: a simultaneous procedure in 79 patients. Acta Orthop Belg 2000;66:265-71.

10. Parvizi J, Tarity TD, Herz A, et al. Ninety-day mortality after bilateral hip arthroplasty. J Arthroplasty 2006;21:931-4.

11. Parvizi J, Pour AE, Peal EL, et al. One-stage bilateral total hip arthroplasty compared with unilateral total hip arthroplasty: a prospective study. J Arthroplasty 2006;21(Suppl 2):26-31

12. Macaulay W, Salvati EA, Sculco TP, Pellicci PM. Single-stage bilateral total hip arthroplasty. J Am Acad Orthop Surg 2002;10:217-21.

13. Jewett BA, Collis DK. Sequential bilateral total hip replacement during the same hospitalization. Clin Orthop 2005:441:256-61.
14. Alfaro-Adrián J, Bayona F, Rech JA, Murray DW. One- or two-stage bilateral total hip replacement. J Arthroplasty 1999;14:439-45.

15. Bhan S, Pankaj A, Malhotra R. One- or two-stage bilateral total hip arthroplasty: a prospective, randomised, controlled study in an Asian population. J Bone Joint Surg [Br] 2006;88-B:298-303

16. Lorenze M, Huo MH, Zatorski LE, Keggi KJ. A comparison of the cost effectiveness of one-stage versus two-stage bilateral total hip replacement. Orthopedics 1998:21:1249-52

17. Cammisa FP, O'Brien SJ, Salvati EA, et al. One-stage bilateral total hip arthroplasty: a prospective study of perioperative morbidity. Orthop Clin North Am 1998:19:657-68.

18. Reuben JD, Meyers SJ, Cox DD, et al. Cost comparison between bilateral simultaneous, staged, and unilateral total joint arthroplasty. J Arthroplasty 1998;13:172-9.

19. Owens WD, Felts JA, Spitznagel EL. ASA physical status classification: a study of consistency ratings. Anesthesiology 1978:49:239-43.

20. Dawson J, Fitzpatrick R, Carr A, Murray D. Questionnaire on the perceptions of patients about total hip replacement. J Bone Joint Surg [Br] 1996;78-B:185-90.

21. Pynsent PB, Adams DJ, Disney SP. The Oxford hip and knee outcome questionnaires for arthroplasty. J Bone Joint Surg [Br] 2005;87-B:241-8.

22. No authors listed. Department of Health. National Tariff 2006/2007. Department of Health, London, United Kingdom, January 2006.

23. R Development Core Team. R: a language and environment for statistical computing. R Foundation for Statistical Computing, Vienna, Austria, 2006. ISBN 3-900051070-0. http://www.R-project-org (date last accessed April 2007) 